\title{
Phylogenetic analysis of some hard ticks from India using mitochondrial 16s rDNA
}

\author{
Harpreet Kaur*, Shivani Chhillar \\ Department of Zoology and Environmental Sciences, Punjabi University, Patiala-147002, Punjab, India.
}

\begin{tabular}{|c|c|}
\hline ARTICLE INFO & ABSTRACT \\
\hline Article history: & \multirow{8}{*}{$\begin{array}{l}\text { The present study was conducted to analyze inter-relationships between Indian hard tick using mitochondrial } 16 \mathrm{~s} \\
\text { rDNA. The sequence alignment consisted of } 85 \text { sequences, } 32 \text { sequences of } 16 \mathrm{~s} \text { rDA belonging to } 7 \text { species of } \\
\text { two genera viz. Rhipicephalus and Hyalomma generated from PCR amplified products and } 53 \text { sequences of hard } \\
\text { ticks from India available in genbank database. The NJ analyses conducted in MEGA6 revealed that } \\
\text { Haemaphysalinae is basal to the clade of Rhipicephalinae + Hyalomminae in the metastriate lineage while } \\
\text { Ixodinae was basal in Ixodidae. There were two large clades, one clade of Hyalomma anatolicum, Hy. } \\
\text { excavatum, Hy. hussaini and Hy. brevipunctata and second clade of Rhipicephalus (Rhipicephalus) + } \\
\text { Rhipicephalus (Boophilus). The results provide evidence for the contention of polyphyly of Rh. (Rh.) sanguineus } \\
\text { and species complex status of } R h \text {. (B.) microplus. A further molecular study from wider distributional area using } \\
\text { more genetic markers is needed to confirm these observations. }\end{array}$} \\
\hline Received on: 01/04/2016 & \\
\hline Revised on: $18 / 04 / 2016$ & \\
\hline Accepted on: $29 / 04 / 2016$ & \\
\hline Available online: $04 / 05 / 2016$ & \\
\hline Key words: & \\
\hline Phylogeny; Ixodidae; $16 \mathrm{~s}$ & \\
\hline rDNA; Hard ticks; India. & \\
\hline
\end{tabular}

\section{INTRODUCTION}

India is predominantly an agricultural country with about $70 \%$ of its population dependent on income from agriculture [1]. The livestock sector especially the dairy sector comprising of approximately 199 million cattle and 105 million buffaloes in India is an important part of the rural agribusiness Indian economy [1]. As tick species parasitizing buffaloes and cattle are similar so the threat of tick borne diseases carried from cattle to buffalo and vice versa is possible and equal attention to the health care of cattle and buffalo should therefore be taken [2]. Ghosh and Nagar [1] have reviewed the various tick borne diseases threatening livestock in India and the recent report of spread of Kyasanur forest disease (KFD) from endemic regions in South India to other regions [3] is very alarming so it is all the more pertinent to have knowledge of tick distribution, speciation and evolution. Ticks are classified in the sub-order Ixodida of the order Parasitiformes, one of the two orders of mites (Acari) consisting of about 900 species divided into two major families: Argasidae Canestrini, 1890 of soft ticks and Ixodidae Murray, 1877 of hard ticks. The third family Nuttalliellidae Schulze, 1935 contains

\footnotetext{
* Corresponding Author

Harpreet Kaur, Department of Zoology and Environmental Sciences, Punjabi University, Patiala-147002, Punjab, India.

Email:harpreetbimbra@gmail.com
}

only a single species Nuttalliella namaqua Bedford, 1931 in a single genus Nuttalliella Bedford, 1931. In the last two decades, molecular phylogenetics has revolutionized the phylogeny and systematics of Arthropods [4], especially Arachnids [5] and Insects [6]. The family Ixodidae of prostriate and metastriate hard ticks has 6 subfamilies Ixodinae, Bothriocrotoninae, Amblyomminae, Haemaphysalinae, Hyalomminae and Rhipicephalinae [7-11]. Recently, there have been reports of prevalence of sibling/cryptic species in different hard tick genera viz. Rhipicephalus, Rhipicephalus (Boophilus), Haemaphysalis and Hyalomma Koch, $1844[12,13]$. Thus there can be possible difficulties in the study of disease transmission and vector control as proper identification of the vector and understanding of the relationships between closely related species is a must for devising any effective control strategy [14-16]. The traditional morphology based identification is sometimes problematic due to variations caused by blood meal [17] and chances of geographical strains of tick species having different vectorial capacity [18-20], genetic introgression, fertile hybrids [21-22], and resistance to acaricides [23] are always there. During the past two decades several molecular markers have been used to resolve relationships and solve problems facing systematics of hard ticks in the family Ixodidae [24-40]. In this context, there is lack of any study on molecular analysis of hard ticks from the India [2, 41]. This crucial gap in information related to hard ticks prompted us to carry out molecular investigation on members of the family Ixodidae from India using mitochondrial 16s rDNA sequences. 


\section{MATERIAL AND METHODS}

\subsection{Material}

The hard ticks infesting cattle and buffalo hosts were field collected from different animal farms located in the state of Haryana (India) (Table 1). After initial separation of hard ticks identification up to species level was done by using standard identification keys available [42-46]. The ticks were photographed using a trinocular stereo-zoom microscope (Labomed ${ }^{\mathrm{TM}}$ ) and subsequently preserved in $100 \%$ ethanol in a $-20^{\circ} \mathrm{C}$ deep freezer (Bluestar).

\subsection{DNA extraction}

DNA was extracted from individual hard ticks using DNeasy $^{\circledR}$ DNA isolation kit (Qiagen). For this, individual ticks were crushed with sterile glass pestle in liquid nitrogen and subsequently DNA was extracted by following the protocol provided with the kit. The DNA was quantified using Tecan's Infinite ${ }^{\circledR}$ NanoQuant and stored at $4{ }^{\circ} \mathrm{C}$. Quality of DNA was checked by resolving on $0.8 \%$ Agarose gels using standard procedure.

\subsection{PCR amplification and sequencing}

PCR was performed to amplify 16s rDNA from individual hard tick DNA samples with the following primer pairs: S16S FP (5'-CTGCTCAATGAATATTTAAATTGC-3') and S16S
RP (5' -CGGTCTAAACTCAGATCATGTAGG-3') [47]. PCR reactions were performed in $25 \mu 1$ reaction mixture that had $100 \mathrm{ng}$ DNA template and $1.5 \mathrm{U}$ of Taq Polymerase $\left(\mathrm{GeNei}^{\mathrm{TM}}\right)$ per reaction along with standard reaction ingredients. The PCR cycling conditions set in the program were as follows: initial denaturation at $94^{\circ} \mathrm{C}$ for 3 min followed by 30 cycles of $94^{\circ} \mathrm{C}$ for $30 \mathrm{sec}$ (denaturation), $50^{\circ} \mathrm{C}$ for $40 \mathrm{sec}$ (annealing), $72^{\circ} \mathrm{C}$ for $40 \mathrm{sec}$ (extension) and a final extension step of $72^{\circ} \mathrm{C}$ for $5 \mathrm{~min}$. PCR products were resolved on $2 \%$ Agarose gels and compared with 100bp DNA standard ladder as the expected product size was in range of 420-440bp. PCR products were purified by using Geneipure $^{\mathrm{TM}}$ Quick PCR Purification kit $\left(\mathrm{GeNei}^{\mathrm{TM}}\right)$ and sent for commercial DNA sequencing to $1^{\text {st }}$ base sequencing service (Malaysia).

\subsection{Sequence details and analysis}

A total of 32 sequences were generated for $16 \mathrm{~s}$ rDNA of 7 species of two hard tick genera during the present study while 53 sequences of hard ticks of various species from India available in the genbank database were retrieved and used for deriving phylogenetic relationships (Table 2). Multiple sequence alignment of eighty five $16 \mathrm{~s}$ rDNA sequences was generated with Muscle software tool executed in MEGA6 phylogenetic analysis software [48]. The alignment was manually edited to remove any alignment errors and exported as mega and fasta format files.

Table 1: The details of hard tick populations analysed during the present study from Haryana (India).

\begin{tabular}{|c|c|c|c|c|}
\hline $\begin{array}{c}\text { S. } \\
\text { No }\end{array}$ & Place of Collection & Species Identified & $\begin{array}{c}\text { Species } \\
\text { code used }\end{array}$ & $\begin{array}{c}\text { Longitude and } \\
\text { Latitude }\end{array}$ \\
\hline 1 & NDRI Karnal & Rhipicephalus (R) microplus (Canestrini, 1888) & RBM & $\begin{array}{l}29.703504 \\
76.983218\end{array}$ \\
\hline 2 & Chopra Colony, Rohtak Road, Gohana & Rhipicephalus (B) microplus (Canestrini, 1888) & RBM & $\begin{array}{l}29.127408 \\
76.698571\end{array}$ \\
\hline 3 & Nuran Khera, Jind Road, Gohana & Hyalomma brevipunctata Sharif, 1928 & HB & $\begin{array}{l}29.203916 \\
76.581767\end{array}$ \\
\hline 4 & Gharaunda City & Rhipicephalus (B) decoloratus (Koch, 1844) & RBD & $\begin{array}{l}29.539130 \\
76.967769\end{array}$ \\
\hline 5 & Hansi Road, Karnal & Hyalomma excavatum Koch, 1844 & $\mathrm{HE}$ & $\begin{array}{l}29.687237 \\
76.974474\end{array}$ \\
\hline 6 & Arainpura, Gharaunda, Karnal & Rhipicephalus (B) microplus (Canestrini, 1888) & RBM & $\begin{array}{l}29.548281 \\
77.016225\end{array}$ \\
\hline 7 & Village Thuska Mahra, Rohtak Road, Gohana & Rhipicephalus $(R)$ sanguineus (Latreille, 1806) & RRS & $\begin{array}{l}29.095420 \\
76.688218\end{array}$ \\
\hline 8 & Ashok Vihar, Sonepat & Hyalomma excavatum Koch, 1844 & $\mathrm{HE}$ & $\begin{array}{l}28.995288 \\
77.006662\end{array}$ \\
\hline 9 & Garhi Brahmanan, Sonepat & Hyalomma anatolicum Koch, 1844 & HA & $\begin{array}{l}28.994380 \\
76.994348\end{array}$ \\
\hline 10 & Gangana, Jind Road, Gohana & Hyalomma anatolicum Koch, 1844 & HA & $\begin{array}{l}29.236950 \\
76.614468\end{array}$ \\
\hline 11 & Badthal, Nilokheri & Rhipicephalus (B) microplus (Canestrini, 1888) & RBM & $\begin{array}{l}29.867340 \\
76.872346\end{array}$ \\
\hline 12 & Kaimla, Gharaunda & Hyalomma hussaini Sharif, 1928 & $\mathrm{HH}$ & $\begin{array}{l}29.505624 \\
76.997015\end{array}$ \\
\hline 13 & Kurana, Israna, Panipat & Rhipicephalus (B) decoloratus (Koch, 1844) & RBD & $\begin{array}{l}29.275754 \\
76.718506\end{array}$ \\
\hline 14 & Namaste Chowk, Karnal & Rhipicephalus (B) decoloratus (Koch, 1844) & RBD & $\begin{array}{l}29.670994 \\
76.990600\end{array}$ \\
\hline
\end{tabular}


Table 2: Accession numbers of 16s rDNA sequences submitted to the GenBank nucleotide database in the study on hard ticks from Haryana (India).

\begin{tabular}{|c|c|c|c|c|}
\hline S.NO & DETAILS OF SEQUENCE & POPULATION & SPECIES & Sequence ID \\
\hline 1. & lcl|1573839 T44 16SR & Badthal & RBM & KP210071 \\
\hline 2. & lcl|1573838 E2 16SR & Namaste chowk & RBD & KP210070 \\
\hline 3. & lcl|1573837 E1 16SR & Namaste chowk & RBD & KP210069 \\
\hline 4. & lcl 1573828 A3 16SF & Gharonda city & RBD & KP210068 \\
\hline 5. & lcl|1573827 A2 16SF & Gharonda city & RBD & KP210067 \\
\hline 6. & lcl|1573826 A1 16SF & Gharonda city & RBD & KP210066 \\
\hline 7. & lcl|1st BASE 1573836D3 & Kaimla & $\mathrm{HH}$ & KP210065 \\
\hline 8. & lcl|1st BASE 1573835D2 16SR & Kaimla & $\mathrm{HH}$ & KP210064 \\
\hline 9. & lcl|1573834 D1 16SR & Kaimla & $\mathrm{HH}$ & KP210063 \\
\hline 10. & lcl|1573833 C3 16SF & Kurana & RBD & KP210062 \\
\hline 11. & lcl|1573832 C2 16SF & Kurana & RBD & KP210061 \\
\hline 12. & lcl $1573831 \mathrm{C} 116 \mathrm{SF}$ & Kurana & RBD & KP210060 \\
\hline 13. & lcl|1573830 B2 16SF & Arainpura & RBM & KP210059 \\
\hline 14. & lcl|1573829 B1 16SF & Arainpura & RBM & KP210058 \\
\hline 15. & lcl|1st BASE $1551253 \mathrm{~K} 4$ 16SF & Nurankhera & $\mathrm{HB}$ & KP210057 \\
\hline 16. & lcl|1st BASE 1547348 K1616SR & Badthal & RBM & KP210056 \\
\hline 17. & lcl|1st BASE 1547347 K1516SR & Badthal & RBM & KP210055 \\
\hline 18. & lcl|1 st BASE 1547346 K1416SR & NDRI & $\mathrm{RBM}$ & KP210054 \\
\hline 19. & lcl|1st BASE 1547345 K1316SR & NDRI & RBM & KP210053 \\
\hline 20. & lcl|1 st BASE 1547344 K1216SR & NDRI & RBM & KP210052 \\
\hline 21. & lcl|1st BASE $1547343 \mathrm{~K} 1116 \mathrm{SR}$ & NDRI & RBM & KP210051 \\
\hline 22. & lcl|1 st BASE 1547342 K1016SR & Thuska mahra & RRS & KP210050 \\
\hline 23. & lcl|1st BASE $1547341 \mathrm{~K} 916 \mathrm{SR}$ & Chopra colony & RBM & KP210049 \\
\hline 24. & lcl|1st BASE $1547340 \mathrm{~K} 816 \mathrm{SF}$ & Hansi road & HAE & KP210048 \\
\hline 25. & lcl|1st BASE 1547339 K7 16SF & Hansi road & HAE & KP210047 \\
\hline 26. & lcl|1st BASE 1547338 K6 16SF & Nurankhera & HB & KP210046 \\
\hline 27. & lcl|1st BASE 1547337 K5 16SF & Nurankhera & HB & KP210045 \\
\hline 28. & lcl|1st BASE $1547335 \mathrm{~K} 316 \mathrm{SF}$ & Ashok Vihar & HAE & KP210044 \\
\hline 29. & lcl|1st BASE $1547334 \mathrm{~K} 2$ 16SF & Ashok Vihar & HAE & KP210043 \\
\hline 30. & lcl|1st BASE $1547333 \mathrm{~K} 1$ 16SF & Ashok Vihar & HAE & KP210042 \\
\hline 31. & lcl|1st BASE 1364793 P4 16SF & Gangana & HA & KP210041 \\
\hline 32. & lcl|1st BASE 1364792 P3 16SF & Garhi brahmanan & HA & KJ912623 \\
\hline
\end{tabular}

\subsection{Phylogenetic analysis}

Phylogenetic analysis was performed in MEGA6 [48] using neighbor joining $(\mathrm{NJ})$ method. The best fit model to derive relationships based on the current data set was estimated by using the model test tool in MEGA6 [48] which supported the - Tamura three parameter model + unequal frequency + gamma distribution (TPMuf $+\mathrm{G})$. In all the analysis gaps and missing data were treated as partial deletion with $90 \%$ site coverage cut-off. The phylogenetic trees were constructed using the below mentioned parameters: nucleotide substitution model - Tamura 3-parameter model [49], test of phylogeny - bootstrap method, 1000 replications, substitutions to include - d: transitions + transversion, rates among sites - gamma distributed, pattern among lineages different (heterogeneous) [50].

\section{RESULTS}

\subsection{Tick diversity}

In this context, the culmination of this study from the state of Haryana (India) resulted in identification of seven Ixodid tick species belonging to two genera viz. Hyalomma Koch, 1844 and Rhipicephalus Koch, 1844. Seven tick species that were identified belonging to these two genera are- Hyalomma anatolicum Koch, 1844, Hyalomma excavatum Koch, 1844, Hyalomma hussaini Sharif, 1928, Hyalomma brevipunctata Sharif, 1928, Rhipicephalus (Rhipicephalus) sanguineus (Latreille, 1806), Rhipicephalus (Boophilus) microplus (Canestrini, 1888), and
Rhipicephalus (Boophilus) decoloratus (Koch, 1844). The study revealed that Hyalomma anatolicum and Rhipicephalus (B.) microplus are the most common vector species that infest the buffalo and cattle in Haryana. Hyalomma excavatum Koch, 1844, Hyalomma brevipunctata Sharif, 1928, and Rhipicephalus (Boophilus) decoloratus (Koch, 1844) have been reported during the present study for the first time from the state of Haryana, India.

\subsection{Molecular Phylogeny}

The molecular methods were employed to perform phylogenetic analysis of ticks infesting cattle from Haryana using mitochondrial 16S ribosomal DNA. The sequences obtained during the present study were compared with the sequences from India which resulted in some interesting inferences having consequent implications on the tick molecular evolution and systematics. When the dataset of eighty-five 16s rDNA sequences belonging to members of family Ixodidae from India was analysed it revealed 180 variable sites, 304 conserved sites, 117 parsimony informative sites and 57 singleton sites. When the evolutionary history was inferred for 16s rDNA sequences of the members of the family Ixodidae from India by the Neighbor-Joining method it resulted in a bootstrap consensus tree inferred from 1000 replicates where branches corresponding to partitions reproduced in less than $50 \%$ bootstrap replicates were collapsed (Figure 1a, b, c). The evolutionary distances were computed using the Tamura 3parameter method in which rate variation among sites was modelled with a gamma distribution. 


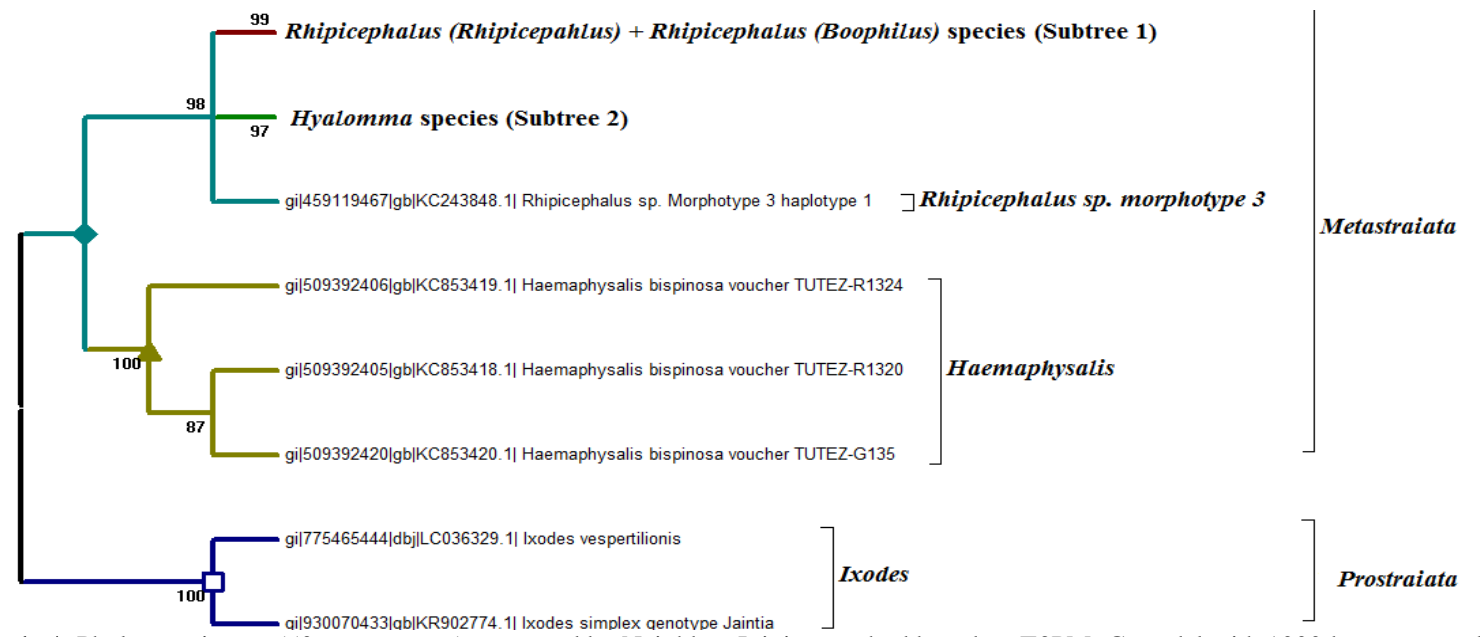

Fig. 1: A-Phylogenetic tree (50\% consensus) generated by Neighbor-Joining method based on T3PM+G model with 1000 bootstrap replicates (values on branches are bootstrap support) for 16s rDNA sequences of hard tick species from India.

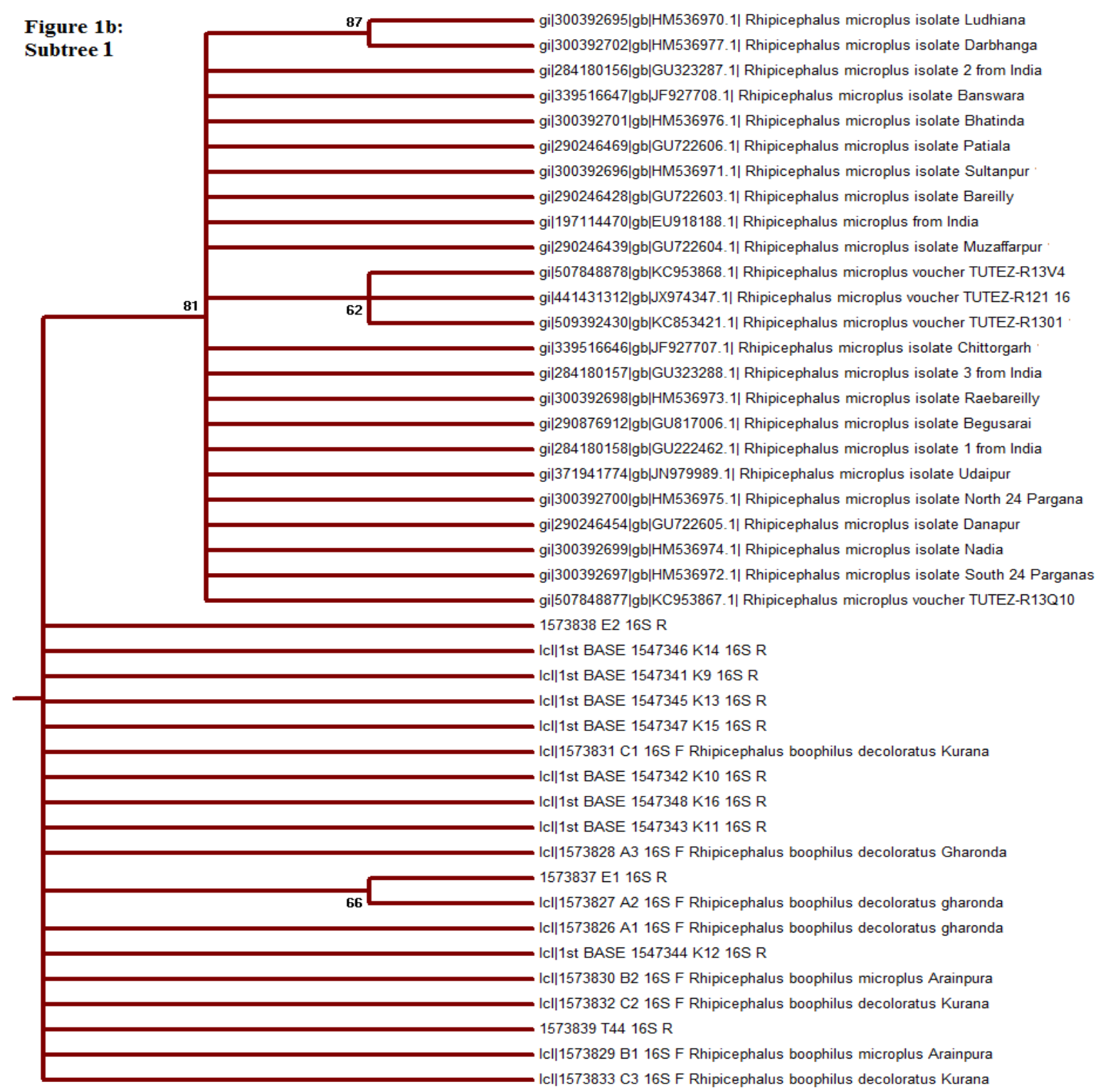

Fig. 1: B-Subtree 1 having Rhipicephalus (Rhipicephalus) + Rhipicephalus (Boophilus) species sequences. 


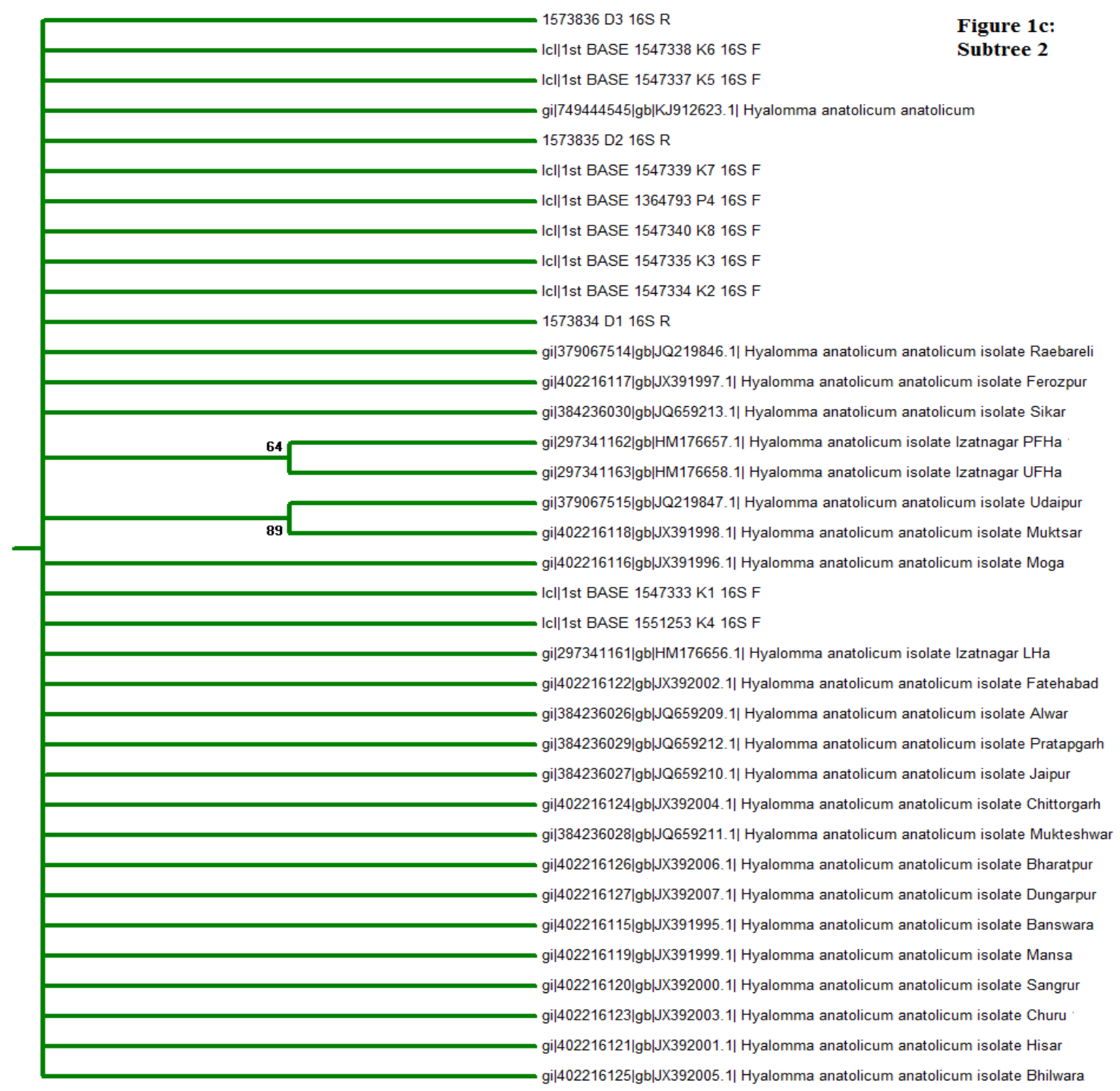

Fig. 1: C-Subtree 2 having Hyalomma species sequences

In the final analysis all positions with less than $90 \%$ site coverage were eliminated resulting in a total of 501 positions in the final dataset. The results revealed that genus Ixodes as the outgroup was most basal. Rhipicephalus (Boophilus) microplus formed clade having 98\% BT support with $R$. (B). decoloratus. Species of genus Hyalomma formed a separate clade with $97 \%$ BT support. Species $R$. morphotype was paraphyletic to the clade of Hyalomma and Rhipicephalus. Haemaphysalis bispinosa was paraphyletic to all the above with $100 \%$ BT support.

\section{DISCUSSION}

\subsection{Inter-relationships within Ixodidae}

A review of literature reveals that there is no explicit study to infer relationships within hard ticks from India but some of the investigations had a few members from India using various molecular markers. The result of this first molecular study from
India have thrown open some important points for discussion as detailed hereunder that will be helpful for future studies on tick distribution, epidemiology, control, and in understanding the tick evolution and systematics. Based on the present $16 \mathrm{~S}$ based phylogeny following points of importance could be inferred viz. subfamily Haemaphysalinae is basal in Metastriate while Rhipicephalus is paraphyletic to Hyalomma and Rhipicephalus (Rhipicephalus) forma a clade with Rhipicephalus (Boophilus).

In this context, Hoogstraal and Aehlimann [18] grouped Haemaphysalinae + Hyalomminae + Rhipicephalinae based on shared presence of hard hooking devices (Spines and Hooks on legs and mouthparts) and the results of the present study are in lines with their hypothesis. Further, the first molecular study based on 16s rDNA conducted to infer phylogenetic relationships of hard and soft ticks by Black and Piesmann [24] revealed that the members of subfamily Hyalomminae claded with members of 
subfamily Rhipicephalinae and over the years different studies have supported monophyly of Metastriata including the present study [7, 25-28, 30, 51].

Similar to present study, Barker and Murrell [10] while reviewing phylogeny of Ixodidae presented a working hypothesis in which the subfamily Haemaphysalinae claded with (Rhipicephalinae + Hyalomminae). Recently, Burger et al., [37] based on their mitochondrial genome analysis also reported paraphyly of genera Rhipicephalus + Hyalomma. In this context, Mans et al., [52] based on their 18s Bayesian analysis also contended that there is very strong support for Metastriata and the clade of Haemaphysalinae + (Rhipicephalinae + Hyalomminae) .

\subsection{Status of different species groups:}

When the individual species groups were considered for the sequences from India the majority of sequences belonged to three species groups' viz. Sanguineus group, Microplus group and Anatolicum group. These are individually discussed hereunder:

\subsubsection{Sanguineus group}

Recently, there has been considerable debate about the status of Rhipicephalus sanguineus sensu stricto as it has been considered as a species complex of 17 closely related species [53, 54, 55], however, there is no consensus [56] and the morphological similarities among ticks belonging to the $R h$. (Rh.) sanguineus group make their identification a difficult task.

Based on the analysis of present data $R h . \quad(R h$. morphotype 3 is paraphyletic with $R h$. (Rh.) sanguineus from Mahra (Haryana) which is suggesting that the former might be a different cryptic/sibling species and that $R h$. (Rh.) sanguineus species complex might be polyphyletic.

\subsubsection{Microplus group}

Rhipicephalus (Boophilus) microplus is a cattle parasite with a one host life cycle. It is thought to have originated in the Indian sub-continent but has now been introduced into many parts of the world including South East Asia with its Host [57-58]. Rhipicephalus (Boophilus) annulatus (Say, 1821) and Rhipicephalus (Boophilus) microplus (Canestrini, 1888) have long been thought to be sister species on the basis of morphology and molecular markers [10]. Labruna et al. [22] analyzed Rh. (B.) microplus from different geographical regions using $12 \mathrm{~s}$ and $16 \mathrm{~s}$ sequences and according to their hypothesis at least two different species share the name of $R h$. (B.) microplus. According to them $R h$. (B.) microplus from India and Nepal have been shown to be highly divergent from $R h$. (B.) microplus from the Americas and Africa [22]. However, the phylogenetic placement of $R h$. (B.) microplus from India and Nepal was not strongly resolved, though $R h$. (B.) microplus from India clustered with $R h$. (B.) annulatus in the 16S rRNA analysis of Labruna et al., [22].

In this context, Estrada-Peña et al., [59] reinstated as a separate species the cattle ticks from Australia previously known as Rh. (B.) microplus as Rhipicephalus (Boophilus) australis (Fuller, 1899). Interestingly, Rh. (B.) decoloratus during the present study claded with from $R h$. (B.) microplus suggesting that $R h$. (B.) microplus is a species complex of at least four species viz. Rh. (B.) microplus, Rh. (B.) annulatus, Rh. (B.) australis, and Rh. (B.) decoloratus and the strains from India and Nepal need to be studied using several molecular markers to discern the sibling/cryptic species and inter-relationships within this important species complex.

\subsubsection{Anatolicum group}

$H$. anatolicum anatolicum and $H$. anatolicum excavatum were subspecies until Apanaskevich and Horak [60] raised those to the rank of species namely Hyalomma anatolicum Koch 1844 and Hyalomma excavatum Koch 1844 based on morphological characters. In this context, a recent study of Hosseini et al., [61] using morphometric methods on male specimens of Hyalomma anatolicum have shown polymorphism in the important taxonomic characters and have recommended more studies on related species for proper identification of species. According to the present analysis there is very strong support for Anatolicum clade of $H y$. anatolicum + excavatum + hussaini + brevipunctata with 97\% BT support supporting the contention of Kaur et al., [62] that it might be a group of species.

\section{CONCLUSIONS}

The results of the present study have confirmed some of the existing morphological and molecular hypotheses about hard tick phylogeny. A condensed phylogenetic tree is provided as a reference standard for any future studies from India (Figure 2). Furthermore, information about the inter-relationships of taxa not previously included in any phylogenetic study has been provided. In conclusion, the molecular evidence presented here suggests that $H$. anatolicum, $H$. excavatum, $H$. hussaini and $H$. brevipunctata represent closely related but rapidly diverging taxa, confirms that $R h$. (B.) microplus is a species complex of at least four species, and asserts that Rh. (Rh.) sanguineus species complex might be polyphyletic.

Although the main aim of our study was to provide a phylogenetic tree as the basis for further comparative studies of inter-relationships within the hard ticks from India rather than a detailed analysis of phylogenetic relationships with other genera within family Ixodidae, still our preliminary results does not support merging the subfamily Hyalomminae within subfamily Rhipicephalinae. This hypothesis needs to be tested using more sequences from other genes covering whole of the metastriate lineage.

\section{ACKNOWLEDGEMENTS}

The authors are thankful to The Chairperson, Department of Zoology and Environmental Sciences, Punjabi University, Patiala-147002, Punjab, India, and Dr. A. Kumaresan, Senior Scientist, NDRI, Karnal for providing the laboratory facilities and support. 


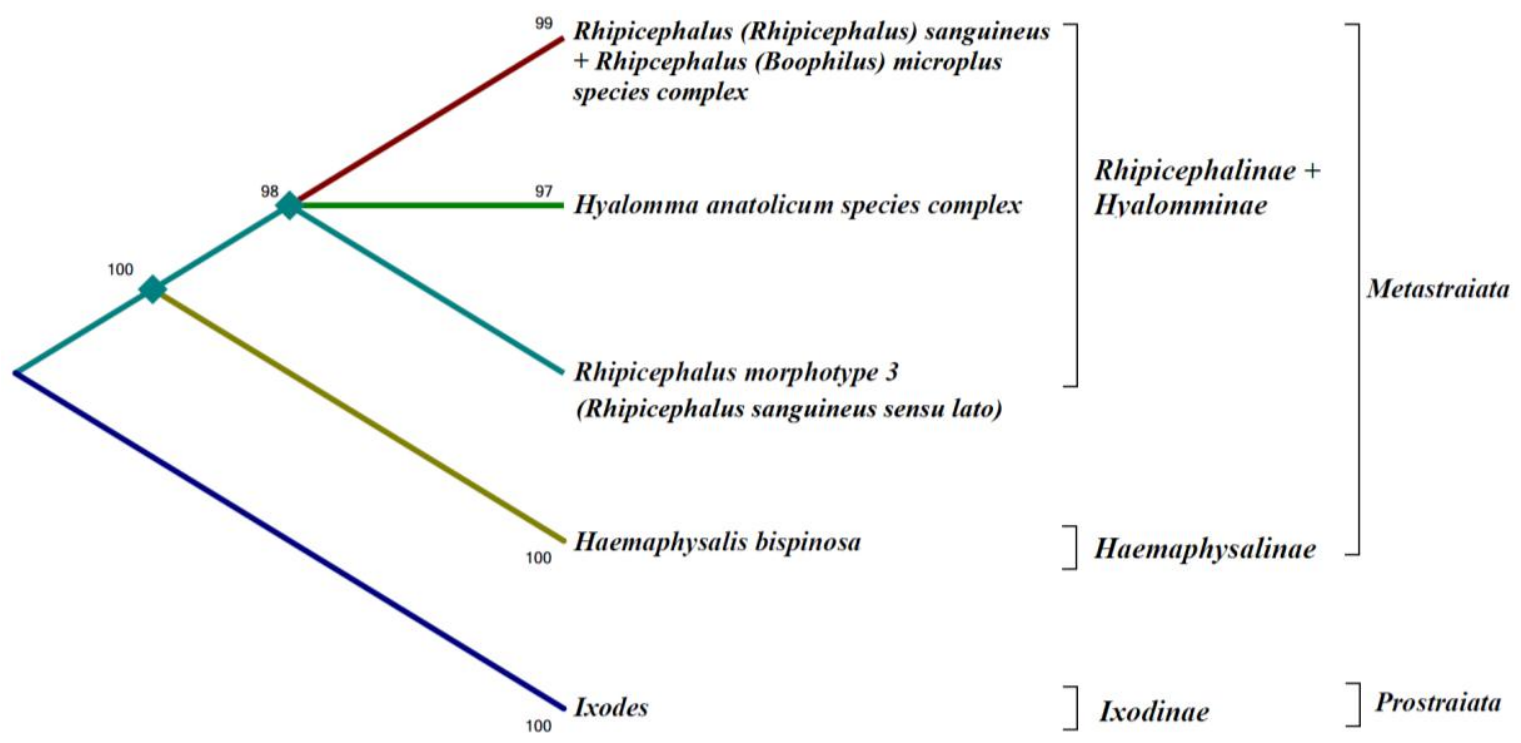

Fig. 2: Condensed Phylogenetic tree summarising the results of the present phylogenetic study on hard tick species from India recommended as a Key for future works

\section{CONFLICT OF INTEREST}

There exists no conflict of interest.

\section{REFERENCES}

1. Ghosh S, Nagar G. Problem of ticks and tick-borne diseases in India with special emphasis on progress in tick control research: A review. Journal of Vector Borne Diseases. 2014; 51: 259-270

2. Miranpuri GS. Ticks parasitizing the Indian buffalo (Bubalus bubalis) and their possible role in disease transmission. Veterinary Parasitology. 1988; 27: 357-362.

3. Murhekar MV, Kasabi GS, Mehendale SM, Mourya DT, Yadav PD, Tandale BV. On the transmission pattern of Kyasanur Forest disease (KFD) in India. Infectious Diseases of Poverty. 2015; 4:37. doi:10.1186/s40249-015-0066-9.

4. Hassanin A. Phylogeny of arthropoda inferred from mitochondrial sequences: strategies for limiting the misleading effects of multiple changes in pattern and rates of substitution. Molecular Phylogenetics and Evolution. 2006; 38: 100-116. Doi: 10.1016/j.ympev.2005.09.012.

5. Masta SE, Longhorn SJ, Boore JL. Arachnid relationships based on mitochondrial genomes: asymmetric nucleotide and amino acid bias affects phylogenetic analyses. Molecular Phylogenetics and Evolution. 2009; 50(1):117-128. doi: 10.1016/j.ympev.2008.10.010.

6. Cruickshank RH. Molecular markers for the phylogenetics of mites and ticks. Systematic and Applied Acarology. 2002; 7: 3-14.

7. Klompen JSH, Oliver-Jr JH, Keirans JE, Homsher PJ. A reevaluation of relationships in the metastraiata (Acari: Parasitiformes: Ixodidae). Systematic Parasitology. 1997; 38: 1-24.

8. Klompen H, Dobson SJ, Barker SC. A new subfamily, Bothriocrotoninae n. subfam., for the genus Bothriocroton Keirans, King \& Sharrad, 1994 status amend. (Ixodida: Ixodidae), and the synonymy of Aponomma Neumann, 1899 with Amblyomma Koch, 1844. Systematic Parasitology. 2002; 53(2):101-7.

9. Horak IG, Camicas JL, Kierans JE. The Argasidae, Ixodidae and Nuttalliellidae (Acari: Ixodida): a world list of valid tick names. Experimental and Applied Acarology. 2002; 28: 27-54

10. Barker SC, Murrell A. Systematics and evolution of ticks with a list of valid genus and species names. Parasitology. 2004; 129: S15-S36.
11. Barker SC, Murrell A. Phylogeny, evolution and historical zoogeography of ticks: a review of recent progress. Experimental and Applied Acarology. 2007; 28: 55-68

12. Liu GH, Chen F, Chen YZ, Song HQ, Lin RQ, Zhou DH. Complete mitochondrial genome sequence data provides genetic evidence that the brown dog tick Rhipicephalus sanguineus (Acari: Ixodidae) represents a species complex. Biological Sciences. 2013; 9(4): 361-369.

13. Burger TD, Shao R, Barker SC. Phylogenetic analysis of mitochondrial genome sequences indicates that the cattle tick, Rhipicephalus (Boophilus) microplus, contains a cryptic species. Molecular Phylogenetics and Evolution. 2014a; 76: 241-253.

14. Klompen, JSH, Black WCIV, Keirans JE, Oliver JHJr. Evolution of ticks. Annual Reviews of Entomology. 1996; 41: 141-161.

15. Jongejan F, Uilenberg G. The global importance of ticks. Parasitology. 2004; 129: S3-S14.

16. Ghosh S, Azhahianambi P, Yadav MP. Upcoming and future strategies of tick control: a review. Journal of Vector Borne Diseases. 2007; 44: 79-89.

17. Lv J, Wu S, Zhang Y, Chen Y, Feng C, Yuan X, Jia G, Deng J, Wang C, Wang Q, Mei L, Lin X. Assessment of four DNA fragments (COI, $16 \mathrm{~S}$ rDNA, ITS2, 12S rDNA) for species identification of the Ixodida (Acari: Ixodida). Parasites and Vectors. 2014; 7 (1): 93.

18. Hoogstraal H, Aeschlimann A. Tick-Host Specificity. Bulletin de la Socie'te' Entomologique Suisse. 1982; 55: 5-32.

19. Gou H, Guan G, Liu A, Ma M, Chen Z, Liu Z, Ren Q, Li Y, Yang J, Yin $\mathrm{H}$, Luo J. Coevolutionary analysis of the relationships between piroplasmids and their hard tick hosts. Ecology and Evolution. 2013 3(9): 2985-2993.

20. Lu X, Lin XD, Wang JB, Qin XC, Tian JH, Guo WP, Fan FN, Shao $\mathrm{R}, \mathrm{Xu}$ J, Zhang YZ. Molecular survey of hard ticks in endemic areas of tick borne diseases in China. Ticks and Tick Borne Diseases. 2013; 4(4): 288-296.

21. Rees DJ, Dioli M, Kirkendall LR. Molecules and morphology: evidence for cryptic hybridization in African Hyalomma (Acari: Ixodidae). Molecular Phylogenetics and Evolution. 2003; 27: 131142.

22. Labruna MB, Naranjo V, Mangold AJ, Thompson C, Estrada-Pena A, Guglielmone AA, Jongejan F, de la Fuente J. Allopatric speciation in ticks: genetic and reproductive divergence between geographic 
strains of Rhipicephalus (Boophilus) microplus. BMC Evolutionary Biology. 2009; 9: 46.

23. Shyma KP, Kumar S, Sharma AK, Ray DD, Ghosh S. Acaricide resistance status in Indian isolates of Hyalomma anatolicum. Experimental and Applied Acarology. 2012; 58 (4): 471-481.

24. Black WCIV, Piesman J. Phylogeny of hard- and soft-tick taxa (Acari: Ixodida) based on mitochondrial 16S rDNA sequences. Proceedings of the National Academy of Sciences. U.S.A. 1994; 91 (21): 10034-10038.

25. Black WCIV, Klompen JSH, Keirans JE. Phylogenetic relationships among tick subfamilies (Ixodida: Ixodidae: Argasidae) based on the 18s nuclear rDNA gene. Molecular Phylogenetics and Evolution. 1997; 7(1): 129-144.

26. Dobson SJ, Barker SC. Phylogeny of the hard ticks (Ixodidae) inferred from 18s rDNA indicates that the genus Aponomma is Paraphyletic. Molecular Phylogenetics and Evolution. 1999; 11(2): 288-295.

27. Murrell A, Campbell NJH, Barker SC. A total evidence phylogeny of ticks provides insights into the evolution of life cycles and biogeography. Molecular Phylogenetics and Evolution. 2001; 21(2): 244-258.

28. Norris DE, Klompen JSH, Black WCIV. Comparison of the mitochondrial $12 \mathrm{~S}$ and 16S Ribosomal DNA genes in resolving phylogenetic relationships among hard ticks (Acari: Ixodidae). Annals of Entomological Society of America. 1999; 92: 117-129.

29. Beati L, Keirans JE. Analysis of the systematic relationships among ticks of the genera Rhipicephalus and Boophilus (Acari: Ixodidae) based on mitochondrial 12s ribosomal DNA gene sequences and morphological characters. Journal of Parasitology. 2001; 87(1): 32 48.

30. Guglielmone AA, Estrada-Pena A, Mangold AJ, Barros-Battesti DM, Labruna MB, Martins JR, Venzal JM, Arzua M, Keirans JE. Amblyomma aureolatum (Pallas, 1772) and Amblyomma ovale Koch, 1844 (Acari: Ixodidae): hosts, distribution and 16S rDNA sequences. Veterinary Parasitology. 2003; 113 (3-4): 273-288.

31. Chitimia L, Lin RQ, Cosoroaba I, Wu XY, Song HQ, Yuan ZG, Zhu $\mathrm{XQ}$. Genetic characterization of ticks from southwestern Romania by sequences of mitochondrial cox1 and nad5 genes. Experimental and Applied Acarology. 2010; 152: 305-311.

32. Abdigoudarzi M, Noureddine R, Seitzer U, Ahmed J. rDNA-ITS2 identification of Hyalomma, Rhipicephalus, Dermacentor and Boophilus spp. (Acari: Ixodidae) collected from different geographical regions of Iran. Advanced Studies in Biology. 2011; 3(5): 221-238.

33. Song S, Shao R, Atwell R, Barker S, Vankan D. Phylogenetic and phylogeographic relationships in Ixodes holocyclus and Ixodes cornuatus (Acari: Ixodidae) inferred from COX1 and ITS2 sequences. International Journal of Parasitology. 2011; 41: 871-880.

34. Burger TD, Shao R, Beati L, Miller H, Barker SC. Phylogenetic analysis of ticks (Acari: Ixodida) using mitochondrial genomes and nuclear rDNA genes indicates that the genus Amblyomma is polyphyletic. Molecular Phylogenetics and Evolution. 2012; 64: 45-55.

35. Burger TD, Shao R, Labruna MB, Barker SC. Molecular phylogeny of soft ticks (Ixodida: Argasidae) inferred from mitochondrial genome and nuclear rDNA sequences. Ticks and Tick Borne Diseases. 2014; 5: 195-207.

36. Kulakova NV, Khasnatinov MA, Sidorova EA, Adel'shin RV, Belikov SI. Molecular identification and phylogeny of Dermacentor nuttalli (Acari: Ixodidae). Parasitology Research. 2014; 113 (5): 1787-1793

37. Lv J, Wu S, Zhang Y, Zhang T, Feng C, Jia G, Lin X. Development of a DNA barcoding system for the Ixodida (Acari: Ixodida). Mitochondrial DNA. 2014; 25 (2): 142-149.

38. Ghosh S, Bansal GC, Gupta SC, Ray D, Khan MQ, Irshad H, Shahiduzzaman Md, Seitzer U, Ahmed JS. Status of tick distribution in Bangladesh, India and Pakistan. Parasitology Research. 2007; 101 (Suppl 2): s207-s216.
39. Murrell A, Campbell NJ, Barker SC. Mitochondrial 12S rDNA indicates that the Rhipicephalinae (Acari: Ixodida) is paraphyletic. Molecular Phylogenetics and Evolution. 1999; 12: 83-86.

40. Kaiser MN, Hoogstraal H. The Hyalomma ticks (Ixodoidea, Ixodidae) of Pakistan, India and Ceylon, with keys to subgenera and species. Acarologia. 1964; 6 (2): 257-286.

41. Geevarghese G, Dhanda V. The Indian Hyalomma ticks (Ixodoidea: Ixodidae). Indian Council of Agricultural Research, New Delhi; 1987.

42. Mangold JJ, Bargues MD, Mas-coma S. Mitochondrial 16S rDNA sequences and phylogenetic relationships of species of Rhipicephalus and other tick genera among Metastriata (Acari: Ixodidae). Parasitology Research. 1998; 84: 478-484.

43. Keirans JE, Litwak TR. Pictorial Key to the Adults of Hard Ticks, Family Ixodidae (Ixodida: Ixodoidea), East of the Mississippi River. Journal of Medical Entomology. 1989; 26(5): 435-448.

44. Mangold AJ, Bargues MD, Mas-coma S. 18S rDNA gene sequences and phylogenetic relationships of European hard-tick species (Acari: Ixodidae). Parasitology Research. 1998; 60: 31-37.

45. Petney TN, Keirans JE. Ticks of the genera Amblyomma and Hyalomma from South-east Asia. Tropical Biomedicine. 1995; 12: 45-56.

46. Walker AR, Bouattour A, Camicas JL, Estrada-Pena A, Horak IG, Latif AA, Pegram RG, Preston PM. Ticks of domestic animals in Africa: a guide to identification of species, Bioscience Reports, Edinburgh, Scotland, U.K; 2003.

47. Tian Z, Xie J, Yin H, Luo J, Zhang L, Zhang P, Luo J. Discrimination between Haemaphysalis longicornis and $H$ qinghaiensis based on the partial 16S rDNA and the second internal transcribed spacer (ITS-2). Experimental and Applied Acarology. 2011; 54: 165-172.

48. Tamura K, Stecher G, Peterson D, Filipski A, Kumar S. MEGA6: Molecular Evolutionary Genetics Analysis version 6.0. Molecular Biology and Evolution. 2013; 30: 2725-2729.

49. Tamura K. Estimation of the number of nucleotide substitutions when there are strong transition-transversion and $\mathrm{G}+\mathrm{C}$-content biases. Molecular Biology and Evolution. 1992; 9: 678-687.

50. Tamura K, Kumar S. Evolutionary distance estimation under heterogeneous substitution pattern among lineages. Molecular Biology Evolution. 2002; 19: 1727-1736.

51. Crampton A, McKay I, Barker SC. Phylogeny of ticks (Ixodida) inferred from nuclear ribosomal DNA. International Journal for Parasitology. 1996; 26: 511-517.

52. Mans BJ, de Klerk D, Pienaar R, de Castro MH, Latif AA. The Mitochondrial Genomes of Nuttalliella namaqua (Ixodoidea: Nuttalliellidae) and Argas africolumbae (Ixodoidae: Argasidae): Estimation of Divergence Dates for the Major Tick Lineages and Reconstruction of Ancestral Blood-Feeding Characters. Public Library of Science One. 2012; 7(11): e49461. doi:10.1371/journal.pone.0049461

53. Dantas-Torres F, Latrofa MS, Annoscia G, Giannelli A, Parisi A, Otranto D. Morphological and genetic diversity of Rhipicephalus sanguineus sensu lato from the New and Old Worlds. Parasites and Vectors. 2013; 6: 213 LID- 10.1186/1756-3305-6.

54. Pegram RG, Clifford CM, Walker JB, Keirans JE. Clarification of the Rhipicephalus sanguineus group (Acari, Ixodoidea, Ixodidae). II. $R$. sanguineus (Latreille, 1806) and related species. Systematic Parasitology. 1987; 10:27-44.

55. Burlini L, Teixeira KR, Szabo MP, Famadas KM. Molecular dissimilarities of Rhipicephalus sanguineus (Acari: Ixodidae) in Brazil and its relation with samples throughout the world: is there a geographical pattern? Experimental and Applied Acarology. 2010; 50: 361-74 LID - 10.1007/s10.

56. Gray J, Dantas-Torres F, Estrada-Peña A, Levin M. Systematics and ecology of the brown dog tick, Rhipicephalus sanguineus. Ticks and Tick Borne Diseases. 2013; 4:171-180.

57. Hoogstraal H. Argasid and nuttalliellid ticks as parasites and vectors. Advances in Parasitology, 1985; 24: 135-238. 
58. Petney, TN and Keirans, JE. Ticks of the genera Boophilus, Dermacentor, Nosomma and Rhipicephalus (Acari: Ixodidae) in Southeast Asia. Tropical Biomedicine. 1996; 13:73-84

59. Estrada-Pena A, Venzal JM, Nava S, Mangold A, Guglielmone AA, Labruna MB. Reinstatement of Rhipicephalus (Boophilus) australis (Acari: Ixodidae) with redescription of the adult and larval stages. Journal of Medical Entomology. 2012; 49: 794-802.

60. Hosseini A, Dalimi A, Abdigoudarzi M. Morphometric Study on Male Specimens of Hyalomma anatolicum (Acari: Ixodidae) in West of Iran. Iran Journal of Arthropod Borne Diseases. 2011; 5(2): 23-31

61. Kaur H, Chhilar JS, Chhillar S. Mitochondrial 16s rDNA based analysis of some hard ticks belonging to genus Hyalomma Koch, 1844 (Acari:Ixodidae). The Journal of Advances in Parasitology. 2016; 3(2): 32-48.

62. Apanaskevich DA, Horak IG. The genus Hyalomma Koch, 1844. II. Taxonomic status of $H$. (Euhyalomma) anatolicum Koch, 1844 and $H$. (E.) excavatum Koch, 1844 (Acari, Ixoididae) with redescription of all stages. Acarina. 2005; 13(2): 181-197.

\section{How to cite this article:}

Harpreet Kaur, Shivani Chhillar. Phylogenetic analysis of some hard ticks from India using mitochondrial 16s rDNA. J App Biol Biotech. 2016; 4 (03): 024-032. DOI: 10.7324/JABB.2016.40305 